\title{
Multi-Battery-Fed Neutral-Point-Clamped Dc-Ac Converter with SoC Balancing Control to Maximize Capacity Utilization
}

\author{
Sergio Busquets-Monge, Senior Member, IEEE, Alber Filba-Martinez, Member, IEEE, \\ Salvador Alepuz, Senior Member, IEEE, Joan Nicolas-Apruzzese, Member, IEEE, \\ Adria Luque, Alfonso Conesa-Roca, and Josep Bordonau, Member, IEEE
}

\begin{abstract}
This paper studies a multilevel multiphase dcac conversion system configured by a neutral-pointclamped converter fed by multiple battery packs connected in series. A virtual-vector modulation is selected and a state-of-charge (SoC) balancing control is designed to be able to employ the full battery bank capacity, even under different battery initial SoC values or different battery nominal capacities. The SoC balancing among battery packs is accomplished through the multilevel converter operation in a lossless manner, by simply distributing the dc-to-ac power flow among the batteries according to their SoC. A simple average system model is also presented, which allows performing very fast system simulations over long periods of time and serves as a convenient tool to tune the compensator parameters.

The satisfactory performance of the proposed system configuration and control, which can be applied with any number of levels and phases, has been verified through simulations and experiments in a four-level three-phase dc-ac converter fed by three Lithium-ion battery packs. The results prove the feasibility and advantages of the proposed system configuration, which can be used to implement conversion systems with different specifications combining several instances of a standard battery pack and a standard power semiconductor device.
\end{abstract}

Index Terms- Active-clamped, battery, charge balancing, diode-clamped, electric vehicle, multilevel, multiphase, neutral-point-clamped, switching-cell array, traction inverter, transistor-clamped.

Manuscript received June 6, 2018; revised October 25, 2018, and November 30, 2018; accepted January 12, 2019. This work was supported by the Ministerio de Economía, Industria y Competitividad, Spain, under Grant DPI2017-89153-P (AEl/FEDER, UE). (Corresponding author: Sergio Busquets-Monge.)

S. Busquets-Monge, A. Filba-Martinez, J. Nicolas-Apruzzese, A. Luque, and $\mathrm{J}$. Bordonau are with the Electronic Engineering Department, Universitat Politècnica de Catalunya, 08028-Barcelona, Spain (e-mail: sergio.busquets@upc.edu; alber.filba@upc.edu, joan.nicolas@upc.edu,

josep.bordonau@upc.edu).

S. Alepuz is with the Escola Superior Politècnica, Tecnocampus Mataró-Maresme, Universitat Pompeu Fabra, 08302-Mataró, Spain (e-mail: dr.salvador.alepuz@ieee.org).

\section{INTRODUCTION}

$\mathrm{E}_{\mathrm{a} / \mathrm{n}}^{\mathrm{L}}$ LECTRICAL energy storage is nowadays essential in many applications, from the interfacing of renewable energy sources to a grid/load, in order to accommodate the stochastic power delivered by these sources to the power requested by the grid/load, to the powering of autonomous electrical transportation systems [1]. Battery electrical energy storage is the most popular technology for this purpose, with currently a strong research focus on improving its main features (e.g., power and energy density) versus cost. The most elementary building block of a battery is the battery cell, characterized by a given nominal voltage and capacity. Regardless of the chemical materials employed to build the cell, its voltage and current ratings, in the order of a few volts and amperes, are usually modest with regard to many applications. Thus, it is often necessary to combine cells in series and parallel to increase the voltage and current ratings, respectively. The resulting set is often referred as a battery pack. The battery pack also contains auxiliary circuitry, the socalled battery management system (BMS), to monitor the cells voltage, current, and temperature, to disconnect the battery pack in case the monitored variables reach unsafe values, and even to balance the cells state-of-charge (SoC), either by dissipating the energy of the cells with the highest SoC or by transferring energy among cells. The SoC balancing of seriesconnected cells is important because, without the balancing, the used capacity of every cell is limited to the weakest cell capacity, resulting in a substantial loss of overall battery effective capacity.

Systems with embedded batteries feature a wide range of voltage, current, and capacity ratings. One option to meet the system specifications is to build a custom battery pack for each specific application, with a custom number of seriesconnected and parallel-connected cells. However, this leads to a high dispersion of battery packs, which renders it impossible to take advantage of economies of scale. In addition, in systems requiring a relatively high voltage rating (usually to reach a relatively high power rating with reasonable efficiency), a very large number of cells must be connected in series, and then, the BMS circuitry becomes specially complex and inefficient, since a very large number of cells in series must be balanced and the SoC balancing involves substantial losses. 
Another preferred option would be to configure a standard battery pack with a relatively low number of cells in series and parallel, to reach minimum voltage, current, and capacity ratings, and then combine this standard battery pack in series and parallel as needed to reach the different system voltage, current, and capacity specifications. This option allows taking advantage of economies of scale to reduce the battery cost. The SoC balancing of the battery packs connected in series must be then accomplished by the power converter controlling the power flow from/to the battery packs. However, this can be performed very efficiently by simply adjusting the power flow from each battery pack, according to their current SoC. This balancing process does not involve additional losses to those already occurring in the power transfer between the battery and other systems. Therefore, it can be regarded as a lossless SoC balancing process, as opposed to the $\mathrm{SoC}$ balancing of battery cells occurring within the battery pack and controlled by the BMS.

Multilevel converter topologies [2] are a clear candidate to enable this type of configurations which combine several standard battery packs. Besides the advantages outlined above, they also bring other benefits such as lower power conversion losses, lower harmonic distortion, and lower electromagnetic interference.

The main multilevel topologies considered in the literature to integrate battery energy storage belong to the cascaded family (including the cascaded H-bridge and the modular multilevel topologies) [3]-[6], or to the neutral-point-clamped (NPC) family [7]-[13]. In the cascaded topologies, the independent voltage source or capacitor of each converter cell is replaced by a battery pack with eventually a parallel capacitor. In the NPC topology, the series connection of capacitors forming the dc-link is replaced by a series connection of battery packs with eventually parallel capacitors, as depicted in Fig.1. As an exception, some authors consider a single battery connected across the outer terminals of the traditional capacitor-voltage-divider NPC dc-link [7], but this configuration does not allow the balancing of the different battery submodules through the converter operation since there are no connections available from the converter to inner battery points.

Cascaded topologies are less complex if a relatively high number of levels are needed, but NPC topologies present three relevant advantages:

1) In multiphase dc-ac applications at a given constant transferred power, the battery currents are $\mathrm{dc}$ while in cascaded topologies the battery currents are usually pulsating currents which contain low-frequency ac components.

2) All battery packs are connected in series. Therefore, the voltages of the battery pack terminals do not oscillate at high frequency among each other and ground, as it is the case in a cascaded topology, leading to reduced electromagnetic interference.

3) From an implementation point of view, NPC topologies allow the decoupling of the system into two blocks: the energy storage block, formed by the series connection of battery packs, and the power conversion block, formed by the NPC converter, essentially containing power semiconductor devices. Since each of these two blocks contain homogeneous components, a high level of integration can be achieved in their implementation and only one connection among heterogeneous blocks is required. In a cascaded topology, power semiconductor devices are mixed with energy storage devices in every converter cell, which hinders the goal of achieving a compact full system implementation given the large number of required connections among heterogeneous components.

NPC topologies certainly present a higher number of power semiconductor devices than the conventional two-level topology. However, besides the inherent advantages of multilevel conversion, including the aforementioned increase in the used battery bank capacity under different scenarios, these topologies may present a higher power rating per switch and higher power rating per unit of power semiconductor area, if devices are properly selected and the selected topology operating principle takes advantage of the additional degrees of freedom that a higher number of devices offers, as illustrated in [14].

Very few works in the literature have focused in the study of multi-battery-fed NPC conversion systems [8]-[13], and almost all of them have only considered the three-level case [8]-[12], which is the most simple. In [8] and [9], a nearestthree-vector (NTV) space-vector-modulation (SVM) approach is used, and the batteries $\mathrm{SoC}$ are balanced through a suitable selection of small vectors. Instead, [10] uses a combination of NTV SVM and radial state SVM, the latter replacing the use of medium vectors by the two nearest large vectors. In [11] and [12], a level-shifted carrier-based pulse width modulation (PWM) approach is used, and an offset is added to the modulating waveforms to control the power balance between the two energy storage units connected at the dc-link.

Conceiving a proper modulation and control for this type of system is challenging, mainly due to the following two reasons:

1) The battery packs present time-varying voltages that depend on their SoC, output impedance parameters, and sourced current. The voltages of the different battery packs will eventually be different from each other. If basic conventional modulation techniques are used, based on the assumption that all battery voltages are equal, this will introduce low-frequency distortion in the converter ac terminal voltages. Although some advanced conventional modulation strategies have been proposed for the threelevel case to avoid introducing low-frequency distortion [8]-[9], [11]-[12], these modulation strategies feature a significantly increased computation complexity as a function of the measured battery voltages. In addition, the errors in the battery voltage measurements inevitably lead to low-frequency distortion.

2) The converter modulation and control must be able to balance the $\mathrm{SoC}$ of all battery packs. This implies being able to control and balance the power delivered by each battery pack. As demonstrated in [13], in converters with more than three levels (more than two battery packs in series), when a conventional PWM is used, where each leg only commutates between the two nearest levels to the reference voltage in every switching cycle, then the power delivered by each battery is different, and the power distribution varies with the modulation index. In a 
renewable energy system where each battery pack is fed by a photovoltaic array, [13] proposes to adjust the photovoltaic power connected to each battery and also the battery capacity according to the power distribution that corresponds to the operating point. But, in general, this is not a practical solution, since the system configuration would need to change depending on the operating modulation index value and, in many applications, the modulation index value is not fixed but varies over time.

This paper proposes a simple modulation and control to operate multi-battery-fed multiphase NPC dc-ac conversion systems with any number of levels and phases. Inherently, the applied modulation does not introduce distortion in the resulting ac voltages when operating under different battery voltages. In addition, the proposed modulation and control allow balancing the $\mathrm{SoC}$ of the different battery packs, even under different nominal capacities, different initial SoC, different battery pack aging, different battery technologies, etc., so that the total battery bank capacity can be fully utilized. An accurate and simple average system model is also presented to quickly design the control and evaluate the resulting system performance. For the sake of simplicity, the proposed system is illustrated in the four-level three-phase case, employing three Li-ion battery packs. The extension to other number of levels and phases is fairly straightforward.

The paper is organized as follows. Section II presents the proposed system configuration and selected PWM strategy. Section III derives the system average model. Section IV defines the proposed closed-loop SoC balancing control. Sections V and VI present simulation and experimental results proving the good performance of the proposed system under different operating scenarios. Finally, Section VII outlines the conclusions.

\section{System Configuration AND SELECtEd PWM STRATEGY}

The generic proposed system configuration is depicted in Fig. 1. A set of $N-1$ battery packs is connected in series to form the dc-link of the $N$-level dc-ac converter. A bypass capacitor is connected in parallel with each battery pack to provide a low-impedance path for the high-frequency components of the dc-link currents generated by the converter operation. The NPC converter synthesizes the ac voltages to be applied to a $Z$-phase source or load by means of $Z$ legs. Regardless of the leg implementation (diode-clamped/passiveclamped or transistor-clamped/active-clamped), each leg is functionally equivalent to a single-pole $N$-throw switch, connecting the ac terminal to one and only one of the $N \mathrm{dc}$ link terminals at every point in time. In Fig. 1, the $Z$ converter legs are represented as single-pole $N$-throw switches, where the switch position is indicated with a solid circle.

Although the proposed system configuration can feature any number of dc-link levels and ac phases, in the following, for the sake of simplicity, the discussion and the analysis will focus on the four-level three-phase case, shown in Fig. 2. Fig. 2 considers a three-phase wye-connected resistive-inductive load on the ac side, which is the type of load used in the simulations and experiments presented in subsequent sections.

The PWM strategy from [15], derived from the virtual- space-vector concept, is selected to operate the converter. This strategy can control the average value of the inner dc-link currents $i_{2}$ and $i_{3}$ in every switching cycle. Moreover, it does not need to be modified as a function of the battery voltage values to avoid introducing low-frequency distortion in the ac voltages when the battery voltages are different, as demonstrated in [16] for the three-level case. The first feature is essential to be able to balance the SoC of the battery packs. The second feature simplifies the modulation implementation and makes it robust against voltage measurement errors.

The selected modulation strategy presents four input parameters:

1) The modulation index $m$, defined as the amplitude (peak value) of the fundamental line-to-line ac converter voltage (e.g., $\left.v_{\mathrm{ab}}\right)$ divided by the total dc bus voltage $\left(v_{\mathrm{dc}}=\right.$ $v_{\mathrm{B} 1}+v_{\mathrm{B} 2}+v_{\mathrm{B} 3}$ ). Its value ranges from 0 to 1 in the linear modulation range.

2) The ac-side line-cycle angle $\theta$, defined as the electrical angle of the fundamental component of the converter phase ' $a$ ' voltage.

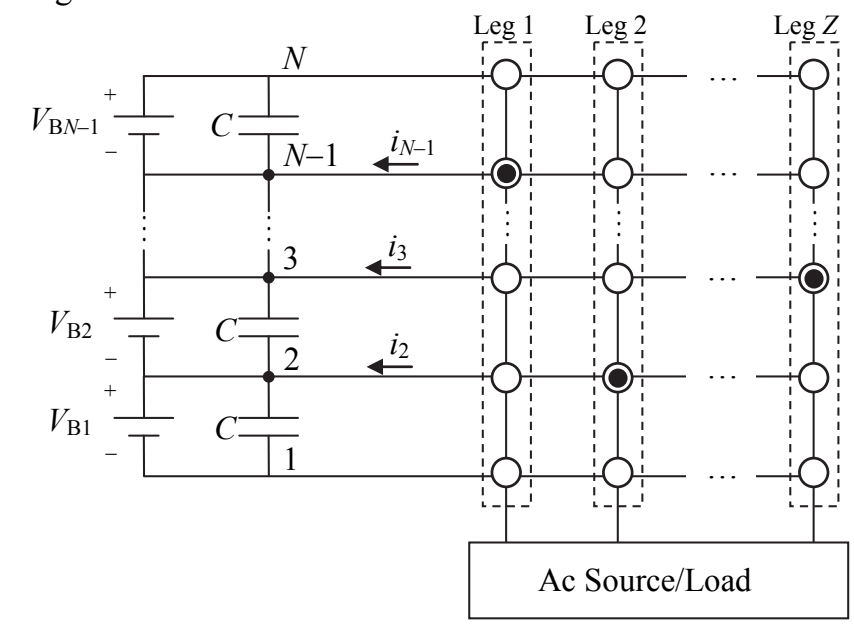

Fig. 1. Functional schematic of an $N$-level $Z$-leg NPC dc-ac converter fed by $N-1$ batteries on the dc side and connected to a generic $Z$-phase source or load on the ac side. Each leg is represented as a single-pole $N$-throw switch. The switch position is indicated by a solid circle.

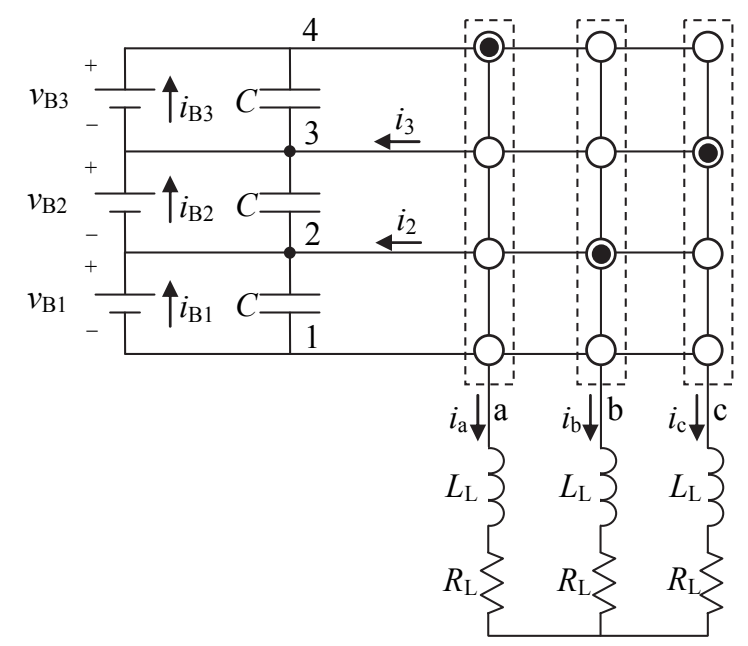

Fig. 2. Functional schematic of a four-level three-leg NPC dc-ac converter fed by 3 batteries on the dc side and connected to a three-phase resistiveinductive load on the ac side. 
3) Parameter $k_{2}$, which represents a normalized value of the desired $i_{2}$ current.

4) Parameter $k_{3}$, which represents a normalized value of the desired $i_{3}$ current.

The values of the leg $x(\in\{\mathrm{a}, \mathrm{b}, \mathrm{c}\})$ duty-ratio of connection to dc-link point $y(\in\{1,2,3,4\})$, designated as $d_{x y}$, which jointly define the modulation strategy, are then calculated as

$$
\begin{aligned}
& \lambda=\frac{1}{1+k_{2} \cdot \frac{v_{\mathrm{B} 2}+v_{\mathrm{B} 3}-v_{\mathrm{B} 1}}{v_{\mathrm{dc}}}+k_{3} \cdot \frac{v_{\mathrm{B} 3}-v_{\mathrm{B} 2}-v_{\mathrm{B} 1}}{v_{\mathrm{dc}}}} \\
& m^{\prime}=\lambda \cdot m \\
& d_{a}^{\prime}(\theta)=(2 / \sqrt{3}) \cdot m^{\prime} \cdot \sin (\theta) \\
& d_{b}^{\prime}(\theta)=(2 / \sqrt{3}) \cdot m^{\prime} \cdot \sin (\theta-(2 \pi / 3)) \\
& d_{c}^{\prime}(\theta)=(2 / \sqrt{3}) \cdot m^{\prime} \cdot \sin (\theta+(2 \pi / 3)) \\
& d_{x 1}^{\prime}(\theta)=0.5 \cdot\left(\max \left[d_{a}^{\prime}(\theta), d_{b}^{\prime}(\theta), d_{c}^{\prime}(\theta)\right]-d_{x}^{\prime}(\theta)\right) \\
& d_{x 4}^{\prime}(\theta)=0.5 \cdot\left(d_{x}^{\prime}(\theta)-\min \left[d_{a}^{\prime}(\theta), d_{b}^{\prime}(\theta), d_{c}^{\prime}(\theta)\right]\right) \\
& d_{x 2}^{\prime}(\theta)=d_{x 3}^{\prime}(\theta)=0.5 \cdot\left(1-d_{x 1}^{\prime}(\theta)-d_{x 4}^{\prime}(\theta)\right) \\
& d_{x 1}=d_{x 1}^{\prime} \cdot\left(1-k_{2}-k_{3}\right) \\
& d_{x 4}=d_{x 4}^{\prime} \cdot\left(1+k_{2}+k_{3}\right) \\
& d_{x 2}=d_{x 2}^{\prime}+k_{2} \cdot\left(d_{x 1}^{\prime}-d_{x 4}^{\prime}\right) \\
& d_{x 3}=d_{x 3}^{\prime}+k_{3} \cdot\left(d_{x 1}^{\prime}-d_{x 4}^{\prime}\right) .
\end{aligned}
$$

Since the three battery voltage values will be typically similar, the calculation of factor $\lambda$ can be simplified to

$$
\lambda=\frac{1}{1+\left(k_{2}-k_{3}\right) / 3} .
$$

If the three battery voltages are not equal, the use of (2) may simply introduce a small error in the resulting amplitude of the ac-voltage fundamental component that will be subsequently corrected by the closed-loop control that determines the value of $m$.

Fig. 3 shows the leg duty-ratio pattern for $k_{2}=k_{3}=0$ over a line cycle. This modulation can be carrier-based implemented through the comparison of three simple modulating signals per leg to a triangular carrier, as shown in Fig. 4. The modulating signals can be obtained from the leg duty-ratio values as

$$
\begin{aligned}
& \bmod _{x 1}=d_{x 1} \\
& \bmod _{x 2}=d_{x 1}+d_{x 2} \\
& \bmod _{x 3}=d_{x 1}+d_{x 2}+d_{x 3}=1-d_{x 4}
\end{aligned}
$$

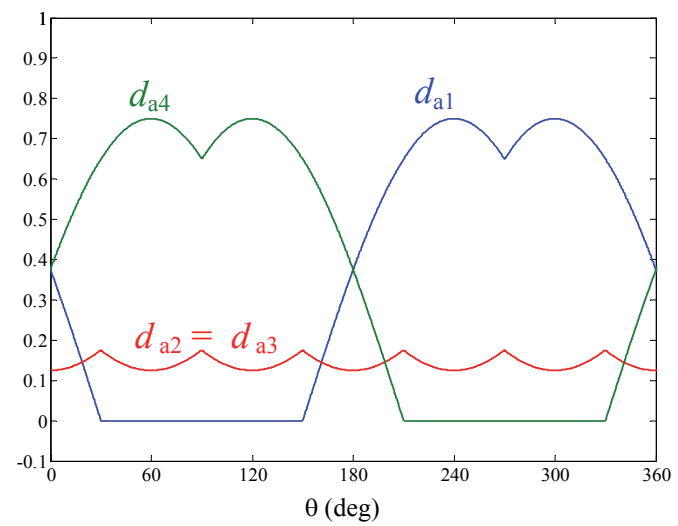

Fig. 3. Leg duty-ratio pattern of the selected PWM for $N=4, Z=3, m=0.75$, and $k_{2}=k_{3}=0$. The plotted waveforms correspond to leg a. The duty ratios for legs $\mathrm{b}$ and $\mathrm{c}$ are the same but phase-shifted $\pm 120^{\circ}$.

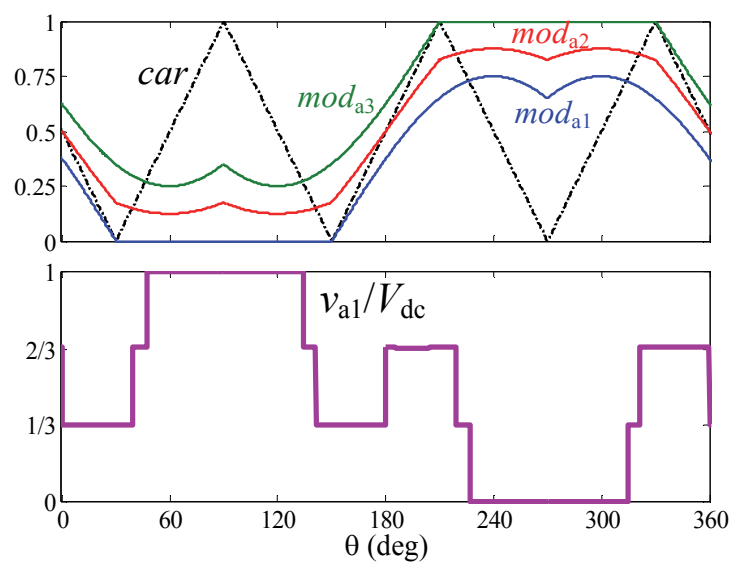

Fig. 4. Carrier-based implementation of the modulation pattern in Fig. 3.

The number of modulating waveforms below the carrier determines the dc-link point to which the leg is connected, generating the leg voltage with reference to point $1, v_{x 1}$. In Fig. 4 , a low ratio of the carrier frequency to the fundamental frequency is used, for the sake of clarity. However, in practice, this ratio is typically much higher.

\section{SYSTEM MODEL}

In this Section, a switching-cycle-average model of the system is derived, in order to be able to conceive and design the closed-loop control. The model allows performing very fast simulations of the system over long periods of time (hours) with good precision.

\section{A. Battery-Pack Model}

In this work, a Lithium-ion battery pack, shown in Fig. 5, is employed. It is formed by 26 cells ( 13 in series -2 in parallel). Table I presents other relevant information. The nominal capacity is $4.3 \mathrm{Ah}$ at $0.2 \mathrm{C}$ discharge rate, according to the battery cell datasheet.

Following the traditional battery modelling approach [17], [18], the Lithium-ion battery pack has been modelled with a Thevenin equivalent circuit, presented in Fig. 6 . The voltage source models the battery open circuit voltage, $V_{\mathrm{OC}}$. Resistance $R_{0}$ represents the battery internal resistance. The remaining series-connected resistive-capacitive networks model the dynamics associated with the diffusion and charge transfer processes that occur within the battery cells. All model parameters vary with the battery SoC, which is defined as

$$
s c(t)=\frac{q(t)}{Q_{\text {nom }}}=s c(0)-\frac{\int_{0}^{t} i_{\mathrm{B}}(t) \cdot \mathrm{d} t}{Q_{\text {nom }}}
$$

where $q(t)$ is the actual capacity or stored charge of the battery pack at time $t$ and $Q_{\text {nom }}$ is its nominal capacity.

Three battery packs have been assembled according to Table I. They have been experimentally characterized using two types of tests. On one hand, discharge tests have been conducted to measure the battery capacity at $1 \mathrm{C}$. The average value of the measured capacity at $1 \mathrm{C}$ has been $4.17 \mathrm{Ah}$. On the other hand, repetitive pulse discharge tests have been performed to estimate the value of all model parameters at 


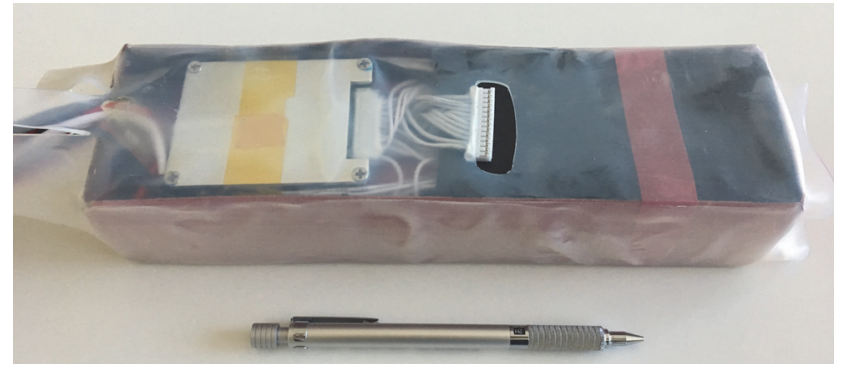

Fig. 5. Selected battery pack.

TABLE I

SELECTED BATTERY PACK

\begin{tabular}{cc}
\hline \hline Item & Value/Description \\
\hline Battery Cell & Samsung ICR18650-22P \\
Cell Chemistry & LiNiMnCoO $_{2}(\mathrm{NMC})$ \\
Configuration & $13 \mathrm{~S}-2 \mathrm{P}$ \\
$V_{\mathrm{Bmin}} / V_{\mathrm{Bnom}} / V_{\mathrm{Bmax}}$ & $38 / 47 / 55 \mathrm{~V}$ \\
$Q_{\text {nom }}$ & $4.3 \mathrm{Ah} @ 0.2 \mathrm{C}$ discharge rate \\
$E_{\mathrm{Bnom}}$ & $202 \mathrm{Wh} @ 0.2 \mathrm{C}$ discharge rate \\
$\begin{array}{c}\text { Type of BMS } \\
\text { balancing }\end{array}$ & Dissipative cell charge balancing during charging \\
\hline \hline
\end{tabular}

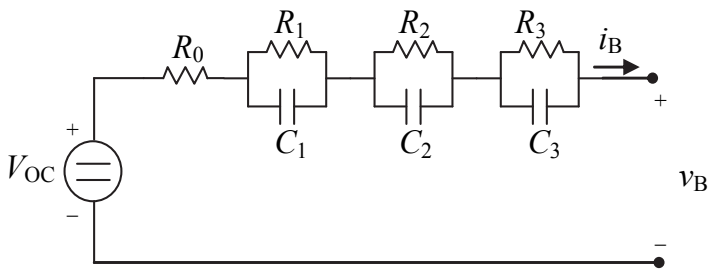

Fig. 6. Battery pack equivalent circuit.

different SoC values. As a result of this characterization process, an equivalent circuit with three RC networks, as shown in Fig. 6, has been deemed satisfactory to approximate the battery behavior. Each RC network reflects a relevant time constant identified in the battery response and it is not necessarily associated to a specific physical phenomenon within the battery. The parameter values at a given SoC are obtained through interpolation from the values obtained experimentally at a specific set of $\mathrm{SoC}$ values. This last set of parameter values can be found in the supplementary MatlabSimulink files.

\section{B. Converter-plus-Ac-System Average Model}

The model of the converter plus ac system should allow computing the battery currents from the value of the battery voltages, the converter operating parameters, and ac source/load parameters. The voltage of each battery pack can be obtained with the model presented in Section III.A, which in turn receives as inputs the battery currents computed here.

Let us assume a lossless converter and let us designate as $p$ the switching-cycle-average power being delivered from the dc side to the ac side (i.e., a positive value means that the power flows from the dc side to the ac side and vice versa for a negative value). In the steady state of a three-phase linear and balanced ac system such as the one depicted in Fig. 2, where the phase currents present a peak value equal to $I$ and a phase-shift angle with reference to the phase voltages equal to $\varphi$,

$$
p=3 \cdot V_{\mathrm{ph}, \mathrm{rms}} \cdot I_{\mathrm{ph}, \mathrm{rms}} \cdot \cos (\varphi)=\frac{\sqrt{3}}{2} \cdot m \cdot v_{\mathrm{dc}} \cdot I \cdot \cos (\varphi) .
$$

At the dc-link, this power can be computed as

$$
p=i_{\mathrm{B} 1} \cdot v_{\mathrm{B} 1}+i_{\mathrm{B} 2} \cdot v_{\mathrm{B} 2}+i_{\mathrm{B} 3} \cdot v_{\mathrm{B} 3} \cdot
$$

Let us now define the common-mode (CM) battery current, from the point of view of the transferred power, as

$$
i_{\mathrm{CM}}=\frac{p}{v_{\mathrm{dc}}}\left(=i_{\mathrm{B} 1} \cdot \frac{v_{\mathrm{B} 1}}{v_{\mathrm{dc}}}+i_{\mathrm{B} 2} \cdot \frac{v_{\mathrm{B} 2}}{v_{\mathrm{dc}}}+i_{\mathrm{B} 3} \cdot \frac{v_{\mathrm{B} 3}}{v_{\mathrm{dc}}}\right) .
$$

Current $i_{\mathrm{CM}}$, shown in Fig. 7, represents a common current of all batteries in charge of transferring power $p$ from the dc side to the ac side. Each battery current $\left(i_{\mathrm{B} 1}, i_{\mathrm{B} 2}\right.$, and $\left.i_{\mathrm{B} 3}\right)$ can be then decomposed as

$$
i_{\mathrm{B} j}=i_{\mathrm{CM}}+i_{\mathrm{DM} j},
$$

where $i_{\mathrm{DM} j}$ is the differential-mode (DM) battery current. These DM currents do not generate power flow from the dcside to the ac-side, but represent a redistribution of power among battery packs, with reference to the case where all battery packs present the same current, equal to $i_{\mathrm{CM}}$. That is, the function of the DM currents is to affect the balance of the battery packs SoC. They can be regarded as balancing currents.

The converter inner dc-link currents $i_{2}$ and $i_{3}$ can only contribute to DM components because the injection of these currents does not modify $p$. They can be decomposed into a DM current flowing through the upper battery packs and a DM current flowing through the lower battery packs, as shown in Fig. 7

$$
\begin{aligned}
& i_{2}=i_{2 \mathrm{~d}}+i_{2 \mathrm{u}} \\
& i_{3}=i_{3 \mathrm{~d}}+i_{3 \mathrm{u}} .
\end{aligned}
$$

Since each inner dc-link current only contributes to a redistribution of power among battery packs, it must be verified that

$$
\begin{aligned}
& i_{2 \mathrm{~d}} \cdot v_{\mathrm{B} 1}=i_{2 \mathrm{u}} \cdot\left(v_{\mathrm{B} 2}+v_{\mathrm{B} 3}\right) \\
& i_{3 \mathrm{~d}} \cdot\left(v_{\mathrm{B} 1}+v_{\mathrm{B} 2}\right)=i_{3 \mathrm{u}} \cdot v_{\mathrm{B} 3} .
\end{aligned}
$$

Combining (9) and (10)

$$
\begin{aligned}
& i_{2 \mathrm{~d}}=\frac{v_{\mathrm{B} 2}+v_{\mathrm{B} 3}}{v_{\mathrm{dc}}} \cdot i_{2} ; \quad i_{2 \mathrm{u}}=\frac{v_{\mathrm{B} 1}}{v_{\mathrm{dc}}} \cdot i_{2} \\
& i_{3 \mathrm{~d}}=\frac{v_{\mathrm{B} 3}}{v_{\mathrm{dc}}} \cdot i_{3} ; \quad i_{3 \mathrm{u}}=\frac{v_{\mathrm{B} 1}+v_{\mathrm{B} 2}}{v_{\mathrm{dc}}} \cdot i_{3} .
\end{aligned}
$$

According to the selected converter modulation, the inner dclink currents are equal to

$$
\begin{aligned}
& i_{2}=2 \cdot \lambda \cdot k_{2} \cdot i_{\mathrm{CM}} \\
& i_{3}=2 \cdot \lambda \cdot k_{3} \cdot i_{\mathrm{CM}}
\end{aligned}
$$

Substituting (12) in (11)

$$
\begin{aligned}
& i_{2 \mathrm{~d}}=2 \lambda k_{2} i_{\mathrm{CM}} \cdot \frac{v_{\mathrm{B} 2}+v_{\mathrm{B} 3}}{v_{\mathrm{dc}}} ; \quad i_{2 \mathrm{u}}=2 \lambda k_{2} i_{\mathrm{CM}} \cdot \frac{v_{\mathrm{B} 1}}{v_{\mathrm{dc}}} \\
& i_{3 \mathrm{~d}}=2 \lambda k_{3} i_{\mathrm{CM}} \cdot \frac{v_{\mathrm{B} 3}}{v_{\mathrm{dc}}} ; \quad i_{3 \mathrm{u}}=2 \lambda k_{3} i_{\mathrm{CM}} \cdot \frac{v_{\mathrm{B} 1}+v_{\mathrm{B} 2}}{v_{\mathrm{dc}}} .
\end{aligned}
$$

Finally, from Fig. 7, (13), and (7), the three battery currents can be calculated as a function of the transferred power $p$, battery voltages, and converter modulation parameters $k_{2}$ and $k_{3}$ as 


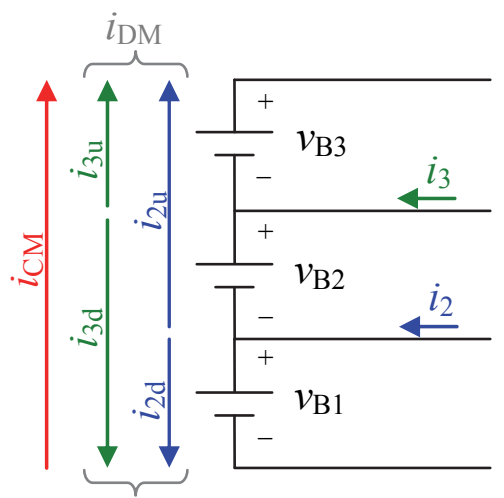

Fig. 7. Decomposition of the battery pack currents into common-mode and differential-mode components. The inner dc-link currents $i_{2}$ and $i_{3}$ only generate differential-mode components.

$$
\begin{aligned}
& i_{\mathrm{B} 1}=i_{\mathrm{CM}}-i_{2 \mathrm{~d}}-i_{3 \mathrm{~d}}=\frac{p}{v_{\mathrm{dc}}}\left(1+2 \lambda\left[-k_{2} \frac{v_{\mathrm{B} 2}+v_{\mathrm{B} 3}}{v_{\mathrm{dc}}}-k_{3} \frac{v_{\mathrm{B} 3}}{v_{\mathrm{dc}}}\right]\right) \\
& i_{\mathrm{B} 2}=i_{\mathrm{CM}}+i_{2 \mathrm{u}}-i_{3 \mathrm{~d}}=\frac{p}{v_{\mathrm{dc}}}\left(1+2 \lambda\left[k_{2} \frac{v_{\mathrm{B} 1}}{v_{\mathrm{dc}}}-k_{3} \frac{v_{\mathrm{B} 3}}{v_{\mathrm{dc}}}\right]\right) \\
& i_{\mathrm{B} 3}=i_{\mathrm{CM}}+i_{2 \mathrm{u}}+i_{3 \mathrm{u}}=\frac{p}{v_{\mathrm{dc}}}\left(1+2 \lambda\left[k_{2} \frac{v_{\mathrm{B} 1}}{v_{\mathrm{dc}}}+k_{3} \frac{v_{\mathrm{B} 1}+v_{\mathrm{B} 2}}{v_{\mathrm{dc}}}\right]\right) .
\end{aligned}
$$

\section{SoC Balancing Closed-Loop Control}

The inner dc-link currents $i_{2}$ and $i_{3}$ generate the DM battery currents, responsible for the balancing of the battery SoC. Assuming that $i_{3}=0$, the expression of $i_{2}$ in (9) can be developed, according to (8) and Fig. 7 as

$$
i_{2}=i_{2 \mathrm{~d}}+i_{2 \mathrm{u}}=\left(-i_{\mathrm{B} 1}+i_{\mathrm{CM}}\right)+\left(\frac{i_{\mathrm{B} 2}+i_{\mathrm{B} 3}}{2}-i_{\mathrm{CM}}\right)=-i_{\mathrm{B} 1}+\frac{i_{\mathrm{B} 2}+i_{\mathrm{B} 3}}{2} .
$$

Substituting the battery currents in (15) by the derivative of the battery charge over time, results in

$$
i_{2}=\frac{\mathrm{d} q_{1}}{\mathrm{~d} t}-\frac{\mathrm{d}\left(\frac{q_{2}+q_{3}}{2}\right)}{\mathrm{d} t}=\frac{\mathrm{d}\left(q_{1}-\frac{q_{2}+q_{3}}{2}\right)}{\mathrm{d} t} .
$$

Assuming that all battery packs present the same nominal capacity, (16) can be rewritten as

$$
i_{2}=Q_{\text {nom }} \cdot \frac{\mathrm{d}\left(s c_{1}-\frac{s c_{2}+s c_{3}}{2}\right)}{\mathrm{d} t}=Q_{\text {nom }} \cdot \frac{\mathrm{d}\left(s c i m b_{2}\right)}{\mathrm{d} t} .
$$

where $\operatorname{scimb}_{2}$ is the imbalance of the batteries SoC calculated at dc-link point 2 .

Similarly, assuming that $i_{2}=0$, the expression of $i_{3}$ in (9) can be developed as

$$
\begin{aligned}
& i_{3}=i_{3 \mathrm{~d}}+i_{3 \mathrm{u}}=\left(-\frac{i_{\mathrm{B} 1}+i_{\mathrm{B} 2}}{2}+i_{\mathrm{CM}}\right)+\left(i_{\mathrm{B} 3}-i_{\mathrm{CM}}\right)=\frac{\mathrm{d}\left(\frac{q_{1}+q_{2}}{2}\right)}{\mathrm{d} t}-\frac{\mathrm{d} q_{3}}{\mathrm{~d} t}= \\
& =\frac{\mathrm{d}\left(\frac{q_{1}+q_{2}}{2}-q_{3}\right)}{\mathrm{d} t}=Q_{\text {nom }} \cdot \frac{\mathrm{d}\left(\frac{s c_{1}+s c_{2}}{2}-s c_{3}\right)}{\mathrm{d} t}=Q_{\text {nom }} \cdot \frac{\mathrm{d}\left(\operatorname{scimb}_{3}\right)}{\mathrm{d} t}
\end{aligned}
$$

where $s c i m b_{3}$ is the imbalance of the batteries SoC calculated at dc-link point 3 .

Therefore, combining (17), (18), and (12), the plant model reduces to

$$
\begin{array}{ll}
\operatorname{scimb}_{2}=\frac{2 \cdot \lambda \cdot i_{\mathrm{CM}}}{s \cdot Q_{\text {nom }}} k_{2} & \left(\text { for } k_{3}=0\right) \\
\operatorname{scimb}_{3}=\frac{2 \cdot \lambda \cdot i_{\mathrm{CM}}}{s \cdot Q_{\text {nom }}} k_{3} & \left(\text { for } k_{2}=0\right)
\end{array}
$$

where $s$ is the Laplace variable, $k_{2}$ and $k_{3}$ are the plant control inputs, and $\mathrm{SoC}$ imbalances $\operatorname{scimb}_{2}$ and $\operatorname{scimb}_{3}$ are the outputs.

In light of (19), the SoC balancing closed-loop control depicted in Fig. 8 is proposed. The value of the $\mathrm{SoC}$ imbalance command $\operatorname{scimb}_{j}{ }_{j}$ is compared to the measured value $\operatorname{scimb}_{j}$. and the error is then processed by a proportional-integral (PI) compensator. Since the plant is coupled (i.e., control input $k_{2}$ affects $\operatorname{scimb}_{3}$ and control input $k_{3}$ affects $\operatorname{scimb}_{2}$ ), it is convenient to multiply the outputs of the compensators by a decoupling matrix. This decoupling matrix is a constant matrix, whose derivation can be found in [19]. The decoupling matrix together with the plant, as a whole, form a new plant where both control loops are decoupled. Finally, the outputs of the decoupling block, which are the command values of $k_{2}$ and $k_{3}$, are limited to avoid unfeasible duty ratio values in the modulator or to limit the DM current in the battery packs.

In Fig. 8, for the sake of simplicity, it is assumed that the power flows from the dc side to the ac side $(p>0)$. However, establishing a control loop that can operate with both power flow directions is fairly simple, as it only requires changing the signs of $k_{2}$ and $k_{3}$ according to the sign of $p$. On another note, the extension of the proposed $\mathrm{SoC}$ balancing control to systems with a higher number of series-connected battery packs and, thus, a higher number of levels, can be accomplished with an analogous procedure as in [15]. For an $n$-level dc-ac conversion system fed by $n-1$ battery packs, $n-2$ control loops are necessary to set the proper values of $k_{2}, k_{3}, \ldots, k_{n-1}$, and the corresponding decoupling matrix can be found in [19].

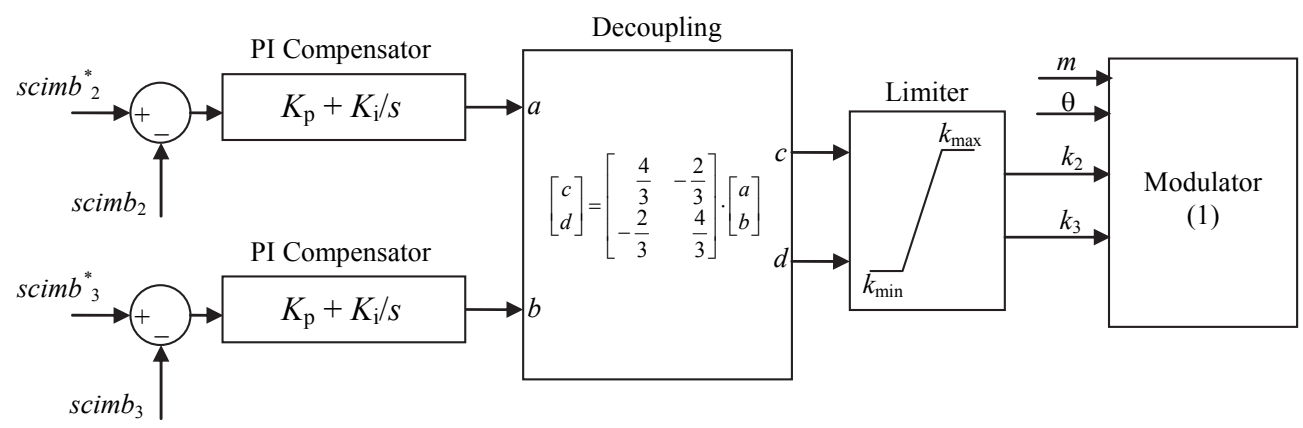

Fig. 8. Proposed SoC balancing closed-loop control $(p>0)$. Feedback variables $s c i m b_{j}$ are computed from the measured battery currents with (4), (17), and (18). 


\section{SimULATION RESULtS}

The performance of the proposed system has been evaluated through simulation in the particular case of Fig. 2. A full battery discharge process at constant modulation index and constant ac load is simulated under different scenarios with the model presented in Section III, implemented in MatlabSimulink. The proposed system performance is indirectly compared to the performance of a conventional system configured by a two-level converter fed by the three seriesconnected batteries, as depicted in Fig. 9. It is an indirect comparison because the behavior of this conventional twolevel system is emulated with the four-level system of Fig. 2 by simply turning OFF the balancing control (i.e., forcing $k_{2}=$ $k_{3}=0$ ). When the balancing control is OFF, the inner dc-link currents $i_{2}$ and $i_{3}$ are equal to zero (on average over every switching cycle), which forces all three battery currents to be equal, as in the conventional two-level case of Fig. 9. Table II gathers the fixed system parameter values and Table III presents the increase in the total energy extracted from the batteries, thanks to the proposed system configuration and control, under eight different discharge cases. The first four cases consider a difference in the initial battery SoC, with the same nominal capacity. These cases emulate the possibility that one or more battery packs feature a lower state of charge due to the fact, for instance, that they feed other auxiliary lowvoltage systems. The last four cases consider a difference in the nominal capacity of batteries, to emulate the performance under batteries with different aging, under a mixture of different battery technologies, or under a mixture of new and second-life batteries.

The proposed configuration and control enables extracting the full energy from all battery packs under all cases, which translates into a substantial total extracted energy increase compared to the conventional two-level case. Fig. 10 presents the evolution over time of key variables under case 1 . With the control OFF (dashed lines), when the SoC of battery pack 2 reaches zero, its voltage decreases down to the minimum allowed value and the corresponding BMS disconnects the battery, forcing the end of the discharging process. At this point, the SoC of battery packs 1 and 3 are at around 0.2 ,

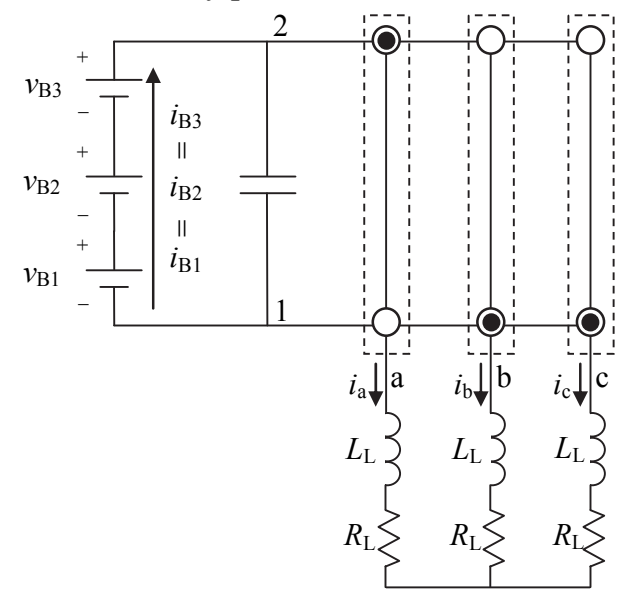

Fig. 9. Functional schematic of a two-level three-leg dc-ac converter fed by 3 batteries on the dc side and connected to a three-phase resistive-inductive load on the ac side. indicating that they still contain a substantial energy that could not be delivered to the load. With the control ON (solid lines), the discharge rate of each battery is adjusted according to its current SoC value, and the discharge process ends with all batteries having an $\mathrm{SoC}$ equal to zero, indicating that all the battery energy has been delivered to the load.

\section{EXPERIMENTAL RESULTS}

An experimental test rig has been assembled to test the proposed system configuration and $\mathrm{SoC}$ balancing control. The system includes three battery packs as described in Table I, $810 \mu \mathrm{F}$ capacitance in parallel with each battery pack at the converter dc-link, a four-level three-leg active-clamped inverter [20] where each leg has been configured from a $6 \times 3$ switching-cell array, as described in [14], and a three-phase

TABLE II

SIMULATION AND EXPERIMENTAL CONDITIONS

\begin{tabular}{cc}
\hline \hline Parameter & Value \\
\hline$m$ & 0.7 \\
Ac fundamental frequency & $50 \mathrm{~Hz}$ \\
Switching frequency & $10 \mathrm{kHz}$ \\
$R_{\mathrm{L}}$ & $8.25 \Omega$ \\
$L_{\mathrm{L}}$ & $3 \mathrm{mH}$ \\
$k_{\min ,} k_{\max }$ & $\pm 0.12($ cases $1,4,5,6,8) ; \pm 0.15$ (cases $2,3,7)$ \\
$K_{\mathrm{p}}$ & 100 \\
$K_{\mathrm{i}}$ & 0.1 \\
$\operatorname{scimb}_{2}{ }_{2}, \operatorname{scimb}_{3}{ }_{3}$ & 0 \\
\hline \hline
\end{tabular}

TABLE III

SiMULATION (EXPERIMENTAL) RESULTS FOR THE INCREASE IN THE TOTAL EXTRACTED BATTERY ENERGY $\left(E_{\mathrm{BT}}=E_{\mathrm{B} 1}+E_{\mathrm{B} 2}+E_{\mathrm{B} 3}\right)$ UNDER DIFFERENT DISCHARGE CASES

\begin{tabular}{|c|c|c|c|c|c|}
\hline Case & $\begin{array}{l}s c_{3}(0) \\
s c_{2}(0) \\
s c_{1}(0)\end{array}$ & $\begin{array}{l}Q_{\text {nom }, 3} \\
Q_{\text {nom }, 2} \\
Q_{\text {nom }, 1} \\
\text { [Ah] } \\
\end{array}$ & $\begin{array}{c}\text { Control OFF } \\
\text { (2-level case) } \\
E_{\mathrm{Bt}}[\mathrm{Wh}]\end{array}$ & $\begin{array}{c}\text { Control ON } \\
E_{\mathrm{Bt}}[\mathrm{Wh}]\end{array}$ & $\Delta E_{\mathrm{Bt}}[\%]$ \\
\hline 1 & $\begin{array}{l}1.0 \\
0.8 \\
1.0\end{array}$ & $\begin{array}{l}4.17 \\
4.17 \\
4.17\end{array}$ & $482(472)$ & $554(545)$ & $15.0(15.0)$ \\
\hline 2 & $\begin{array}{l}1.0 \\
1.0 \\
0.8\end{array}$ & $\begin{array}{l}4.17 \\
4.17 \\
4.17\end{array}$ & $481(473)$ & $554(544)$ & $15.0(15.0)$ \\
\hline 3 & $\begin{array}{l}0.8 \\
1.0 \\
0.8\end{array}$ & $\begin{array}{l}4.17 \\
4.17 \\
4.17\end{array}$ & 475 & 511 & 7.5 \\
\hline 4 & $\begin{array}{l}1.0 \\
0.8 \\
0.8\end{array}$ & $\begin{array}{l}4.17 \\
4.17 \\
4.17\end{array}$ & 475 & 511 & 7.5 \\
\hline 5 & $\begin{array}{l}1.0 \\
1.0 \\
1.0\end{array}$ & $\begin{array}{l}4.17 \\
3.34 \\
4.17\end{array}$ & 485 & 557 & 15.0 \\
\hline 6 & $\begin{array}{l}1.0 \\
1.0 \\
1.0\end{array}$ & $\begin{array}{l}4.17 \\
4.17 \\
3.34\end{array}$ & 485 & 556 & 15.0 \\
\hline 7 & $\begin{array}{l}1.0 \\
1.0 \\
1.0\end{array}$ & $\begin{array}{l}3.34 \\
4.17 \\
3.34\end{array}$ & 481 & 517 & 7.5 \\
\hline 8 & $\begin{array}{l}1.0 \\
1.0 \\
1.0\end{array}$ & $\begin{array}{l}4.17 \\
3.34 \\
3.34\end{array}$ & 481 & 516 & 7.5 \\
\hline
\end{tabular}



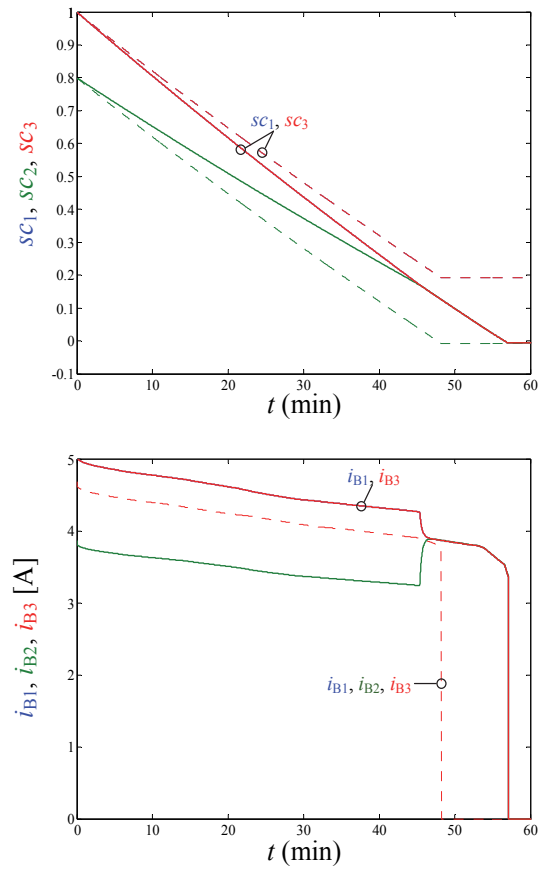
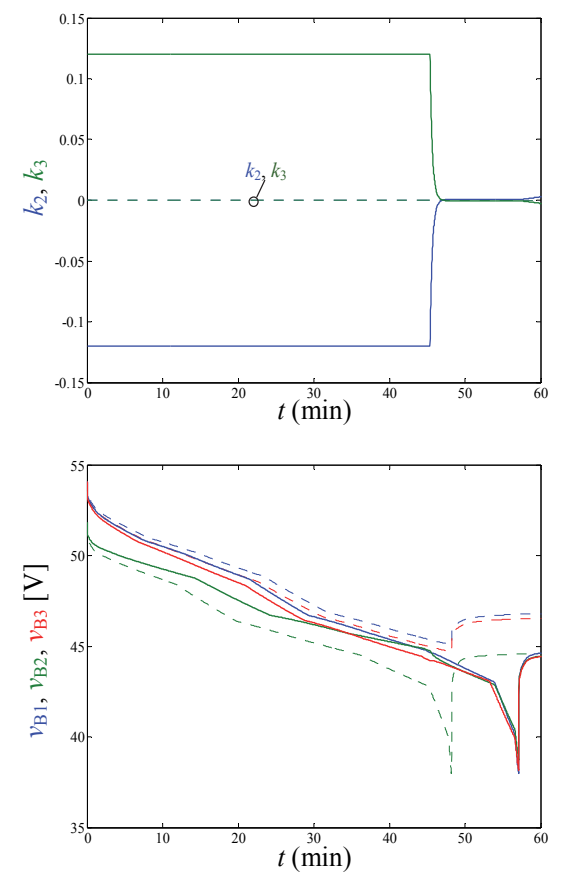
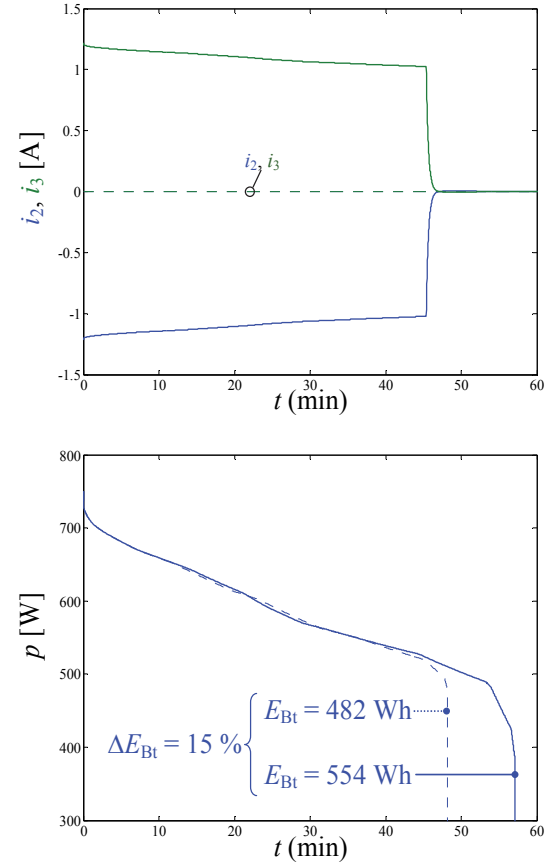

Fig. 10. Simulation results of case 1. Dashed lines: control OFF. Solid lines: Control ON.

passive resistive-inductive load. Fig. 11 shows the converter prototype. The converter is controlled with a dSpace platform, including one DS1006 processor board and three synchronized DS5101 digital waveform output boards, containing each a field-programmable gate array. The battery currents and voltages are sensed to implement the control. The battery discharging tests have been performed under the conditions outlined in Table II. Table III summarizes the experimental results, within parenthesis, under the two cases tested (case 1 and case 2). These results are in good agreement with the simulation study.

Fig. 12 presents the temporal evolution of key variables under case 1 experiment. These waveforms are also in good agreement with the simulation results of Fig. 10. The converter losses and a non-negligible error in the sensed value of battery pack 1 current explain the small differences. The voltage of the battery pack reaching the cutoff condition set by the BMS goes down to zero after the BMS cuts off because the voltage is sensed at the external battery pack terminals, which embrace the BMS circuitry.

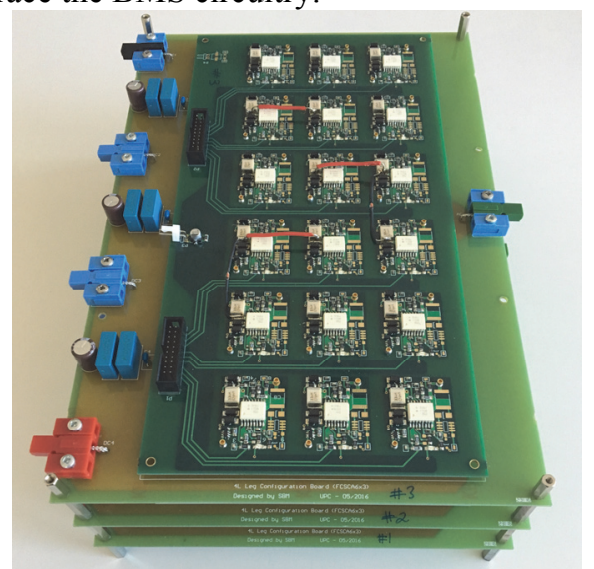

Fig. 11. Four-level three-phase active-clamped dc-ac converter prototype.
Fig. 13 shows key waveforms (battery currents, line-to-line voltages, and phase currents) during a turn-on transient of the $\mathrm{SoC}$ balancing control within the first ten minutes of the discharge process of case 1 . The control is OFF during the left half of the scope capture and it is ON during the right half. Each battery current contains a dc component with some highfrequency ripple. With the control OFF, the dc component of the three battery currents are equal. With the control ON, they change to discharge faster the two battery packs with the highest SoC. It is worth noting that despite the difference in the line-to-line voltages with the control OFF and ON, the phase currents look almost identical. Thus, as stated previously, the control action does not affect the resulting ac currents.

Fig. 14 presents the same key waveforms under two ac load step transients with the balancing control ON. It can be observed that the balancing control performs well under sudden load changes, with the battery currents quickly adjusting their values to the new load condition and permanently preserving their proportion (i.e., $i_{\mathrm{B} 1}=i_{\mathrm{B} 3} \approx 1.3$ $i_{\mathrm{B} 2}$ ) according to the values of the control output parameters $k_{2}$ and $k_{3}$.

Finally, Fig. 15 proves the proper system performance under different modulation index values. In all cases the control manages to adjust the relative discharge rate of each battery pack according to their current relative SoC.

\section{CONCLUSION}

This paper has presented, for the first time, the application of a virtual vector PWM to a multi-battery-fed NPC dc-ac converter, highlighting the advantages of applying this modulation technique; namely, no low-frequency harmonic distortion in the synthesized ac voltage under different values of the battery voltages forming the dc link, it enables using any number of converter levels and phases and thus, it enables 

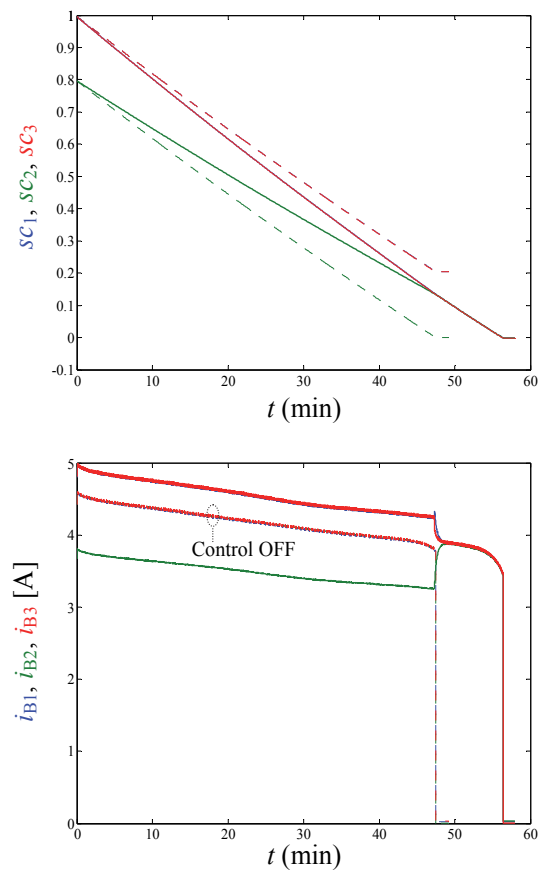
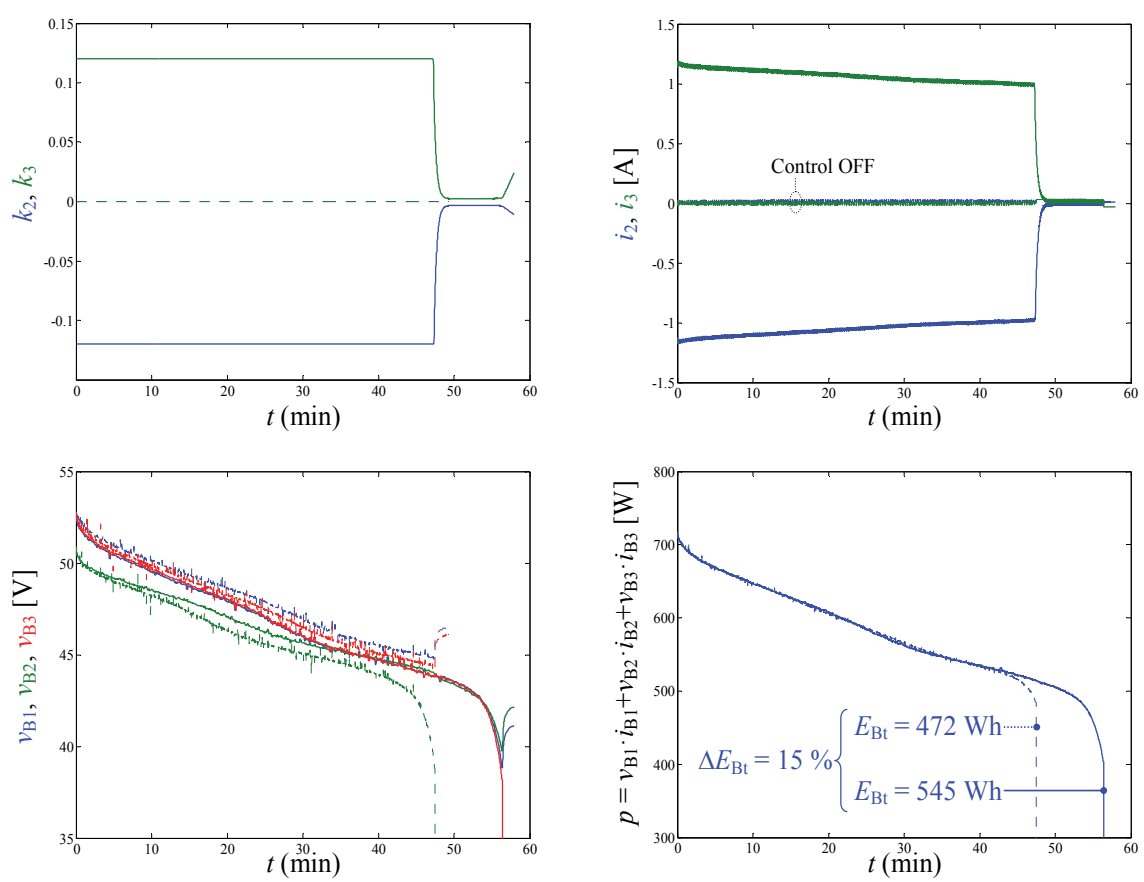

Fig. 12. Experimental results of case 1. Dashed lines: control OFF. Solid lines: Control ON.

a modular design of these systems based on a single standard battery pack and a single switching cell, the converter can be operated with any modulation index and load, etc. The switching-cycle-average full system model (including battery, power converter, and ac source/load) has also been derived. This model has allowed conceiving a novel SoC balancing closed-loop control, it allows performing very fast simulations of the whole system behavior, and it allows adjusting the closed-loop control parameters to achieve the desired performance. The proposed system and system model has been experimentally validated in the particular case of four levels, three ac phases, and Lithium-ion battery packs.

The results obtained with the proposed system configuration and control prove that it is feasible to operate NPC dc-ac converters with any number of levels and phases fed by multiple standard battery packs connected in series, where the dc-ac converter takes over the SoC balancing of the battery packs in a lossless manner, by simply distributing the dc-to-ac power flow among the batteries according to their SoC. This opens the possibility to use this compact and efficient system configuration to implement conversion systems with different voltage, current, and power ratings from a standard battery pack and a standard power semiconductor device at a single voltage and current rating. In addition, since the power converter is able to take care of the balancing of the battery packs, it is feasible to operate with battery packs having different loading, with battery packs experiencing different aging, with battery packs built with different technologies, mixing new and second-life battery packs, and still take advantage of the full capacity available at the battery bank.

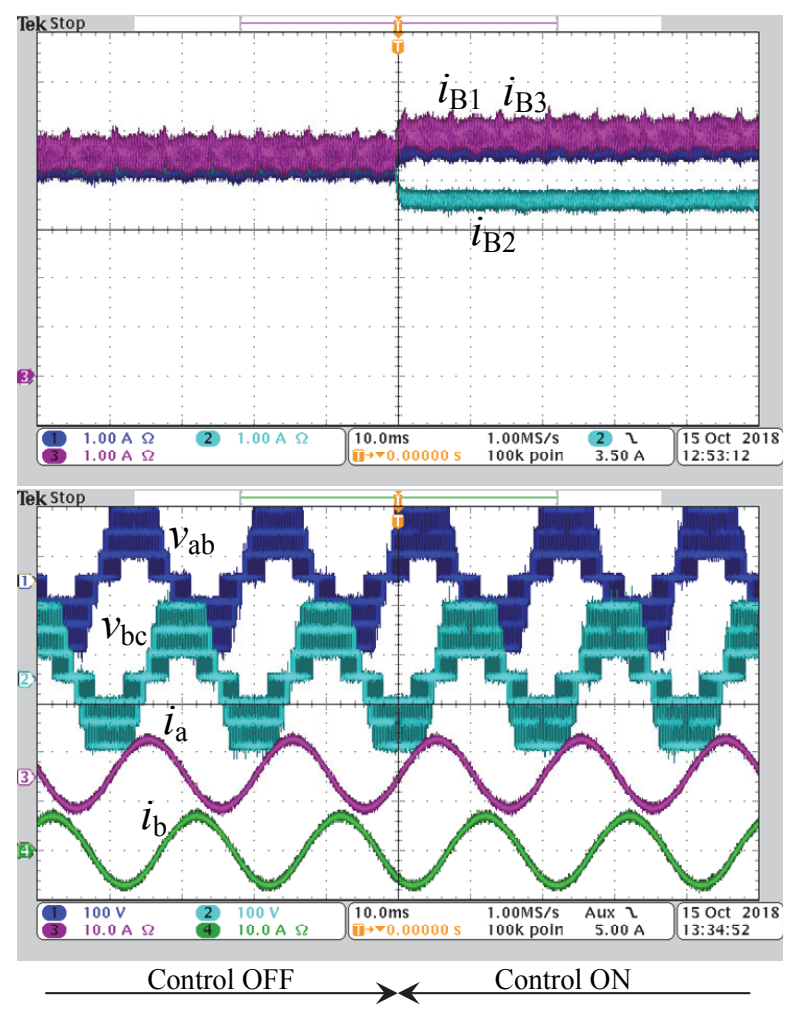

Fig. 13. Experimental results during a turn-on transient of the SoC balancing closed-loop control within the first minutes of the discharge process of case 1 . 

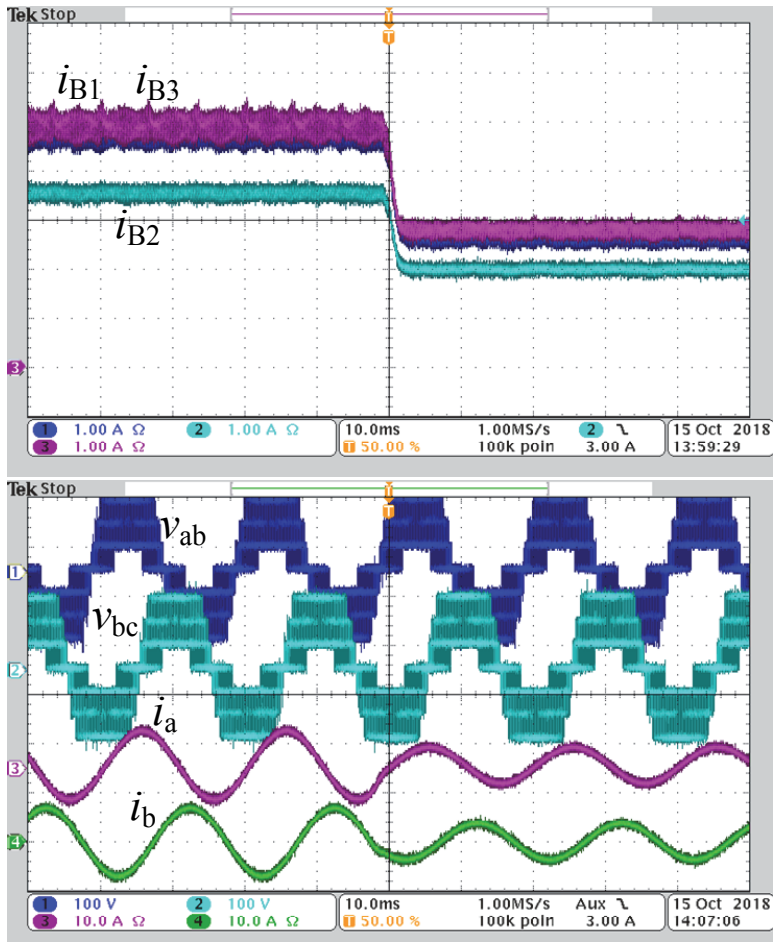

(a)

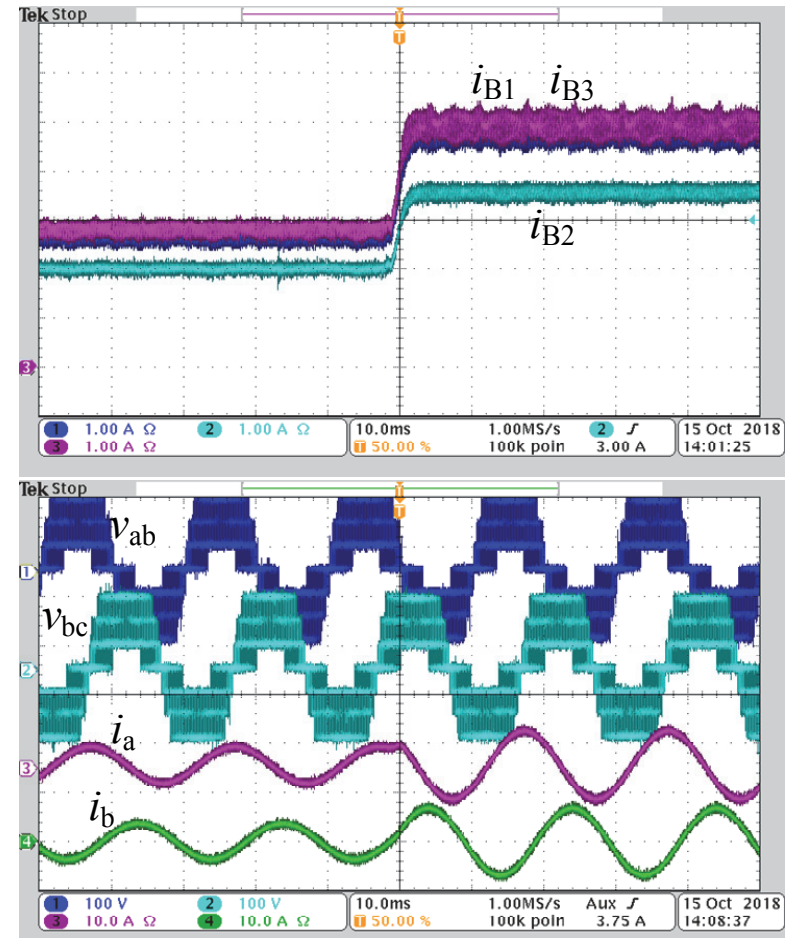

(b)

Fig. 14. Experimental results during an ac load step transient within the first ten minutes of the discharge process of case 1 (control ON). (a). Load step from $R_{\mathrm{L}}$ $=8.25 \Omega$ to $R_{\mathrm{L}}=16.5 \Omega$. (b) Load step from $R_{\mathrm{L}}=16.5 \Omega$ to $R_{\mathrm{L}}=8.25 \Omega$.

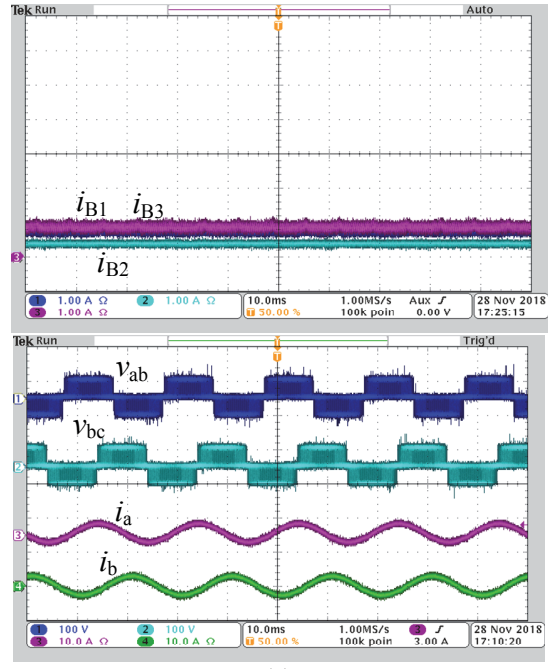

(a)

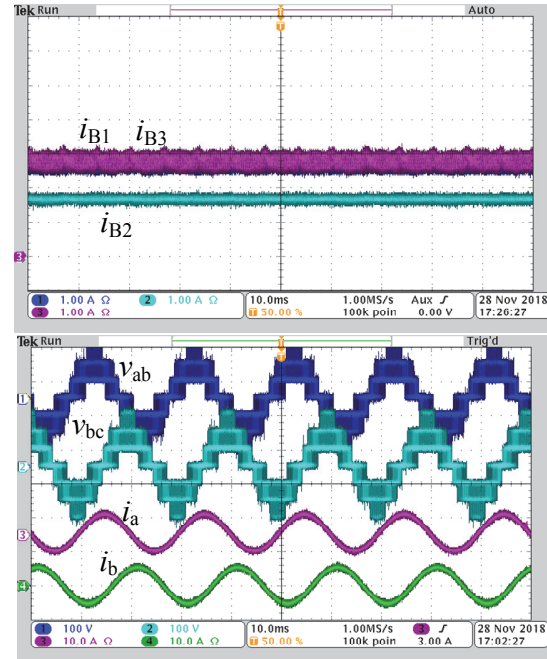

(b)

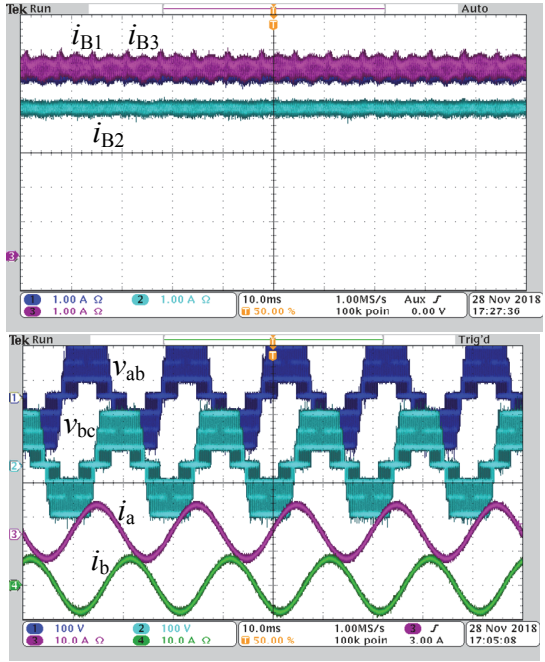

(c)

Fig. 15. Experimental results at the beginning of discharge case 1 (control ON) under different modulation index values. (a) $m=0.25\left(k_{\min }, k_{\max }= \pm 0.3\right)$. (b) $m=$ $0.50\left(k_{\min }, k_{\max }= \pm 0.2\right)$. (c) $m=0.75\left(k_{\min }, k_{\max }= \pm 0.1\right)$.

\section{REFERENCES}

[1] B. Sarlioglu, C. T. Morris, D. Han, and S. Li, "Driving Toward Accessibility: A Review of Technological Improvements for Electric Machines, Power Electronics, and Batteries for Electric and Hybrid Vehicles," in IEEE Ind. Appl. Mag., vol. 23, DOI 10.1109/MIAS.2016.2600739, no. 1, pp. 14-25, Jan.-Feb. 2017.

[2] H. Akagi, "Multilevel converters: fundamental circuits and systems," Proc. IEEE, vol. 105, DOI 10.1109/JPROC.2017.2682105, no. 11, pp. 2048-2065, Nov. 2017.

[3] M. Chen, B. Zhang, Y. Li, G. Qi, and J. Liu, "Design of a multi-level battery management system for a cascade H-bridge energy storage system," in Proc. IEEE Power and Energy Soc. Asia-Pacific Power and Energy Engineering Conference, 2014, DOI 10.1109/APPEEC.2014.7066076, pp. 1-5.
[4] E. Chatzinikolaou and D. J. Rogers, "Cell SoC balancing using a cascaded full-bridge multilevel converter in battery energy storage systems," in IEEE Trans. on Ind. Electron., vol. 63, DOI 10.1109/TIE.2016.2565463, no. 9, pp. 5394-5402, Sept. 2016.

[5] F. Helling, J. Glück, A. Singer, and T. Weyh, "Modular multilevel battery (M2B) for electric vehicles," in Proc. European Conf. on Power Electronics and Applications - IEEE Energy Conversion Congress and Exposition, 2016, DOI 10.1109/EPE.2016.7695480, pp. 1-9.

[6] N. Li, F. Gao, T. Hao, Z. Ma, and C. Zhang, "SOH balancing control method for the MMC battery energy storage system," in IEEE Trans. Ind. Electron., vol. 65, DOI 10.1109/TIE.2017.2733462, no. 8, pp. 65816591, Aug. 2018.

[7] A. Choudhury, P. Pillay, and S. S. Williamson, "Modified DC-bus voltage-balancing algorithm based three-level neutral-point-clamped IPMSM drive for electric vehicle applications," in IEEE Trans. on Ind. Electron., vol. 63, DOI 10.1109/TIE.2015.2478392, no. 2, pp. 761-772, Feb. 2016. 
[8] S. D. G.. Jayasinghe, D. M. Vilathgamuwa, and U. K. Madawala, "Diode-clamped three-level inverter-based battery/supercapacitor direct integration scheme for renewable energy systems," in IEEE Trans. on Power Electron., vol. 26, DOI 10.1109/TPEL.2011.2148178, no. 12, pp. 3720-3729, Dec. 2011.

[9] H. R. Teymour, D. Sutanto, K. M. Muttaqi, and P. Ciufo, "Solar PV and battery storage integration using a new configuration of a three-level NPC inverter with advanced control strategy," in IEEE Trans. Energy Convers., vol. 29, DOI 10.1109/TEC.2014.2309698, no. 2, pp. 354-365, June 2014.

[10] I. Vechiu, A. Etxeberria, H. Camblong, S. Baudoin, and S. Kreckelbergh, "Hybrid energy storage system with unique power electronic interface for microgrids," in Proc. IEEE Power and Energy Soc. Innovative Smart Grid Technologies Europe, 2013, DOI 10.1109/ISGTEurope.2013.6695408, pp. 1-5.

[11] I. Vechiu, A. Etxeberria, Q. Tabart, and R. Lopez, "Operational limits of four wires three levels NPC topology for power quality improvement in weak grids," in Proc. IEEE Int. Conf. on Environment and Electrical Engineering, 2016, DOI 10.1109/EEEIC.2016.7555456, pp. 1-5.

[12] M. Laumen, M. Schubert, A. Bubert, A. Lamprecht, and R. W. De Doncker, "Optimized space vector modulation for DC-link balancing in three-level neutral-point-clamped inverters for electric drives," in Proc. IEEE Int. Conf. on Power Electronics and Drive Systems, 2017, DOI 10.1109/PEDS.2017.8289216, pp. 1,135-1,140.

[13] P. Sarthi, A. M. Rao, and K. SivaKumar, "Analysis for optimal distribution of PV panels and batteries in multilevel inverters," in Proc. National Power Electron. Conf., 2017, DOI 10.1109/NPEC.2017.8310465, pp. 240-245.

[14] S. Busquets-Monge and L. Caballero, "Switching-cell arrays - An alternative design approach in power conversion," IEEE Trans. Industrial Electron., vol. 66, DOI 10.1109/TIE.2018.2816002, no. 1, pp. 25-36, Jan. 2019

[15] S. Busquets-Monge, R. Maheshwari, J. Nicolas-Apruzzese, E. Lupon, S. Munk-Nielsen, and J. Bordonau, "Enhanced dc-link capacitor voltage balancing control of dc-ac multilevel multileg converters," IEEE Trans. Ind. Electron., vol. 62, DOI 10.1109/TIE.2014.2363820, no. 5, pp. 26632672, May 2015.

[16] X. Wu, G. Tan, Z. Ye, G. Yao, Z. Liu, and G. Liu, "Virtual-space-vector PWM for a three-level neutral-point-clamped inverter with unbalanced DC-links," in IEEE Trans. Power Electron., vol. 33, DOI 10.1109/TPEL.2017.2692272, no. 3, pp. 2630-2642, Mar. 2018.

[17] M. Chen and G. A. Rincon-Mora, "Accurate electrical battery model capable of predicting runtime and $\mathrm{I}-\mathrm{V}$ performance," IEEE Trans. Energy Convers., vol. 21, DOI 10.1109/TEC.2006.874229, no. 2, pp. 504-511, Jun. 2006.

[18] N. El Ghossein, J. P. Salameh, N. Karami, M. El Hassan, and M. B. Najjar, "Survey on electrical modeling methods applied on different battery types," in Proc. IEEE Int. Conf. on Technological Advances in Electrical, Electronics, and Computer Engineering, 2015, DOI 10.1109/TAEECE.2015.7113597, pp. 39-44.

[19] S. Busquets-Monge, R. Griñó, J. Nicolas-Apruzzese, and J. Bordonau, "Decoupled dc-link capacitor voltage control of dc-ac multilevel multileg converters," IEEE Trans. Industrial Electron., vol. 63, DOI 10.1109/TIE.2015.2495295, no. 3, pp. 1344-1349, Mar. 2016.

[20] S. Busquets-Monge and J. Nicolas-Apruzzese, "A multilevel activeclamped converter topology - Operating principle," IEEE Trans. Ind. Electron., vol. 58, DOI 10.1109/TIE.2010.2098376, no. 9, pp. 38683878, Sept. 2011.

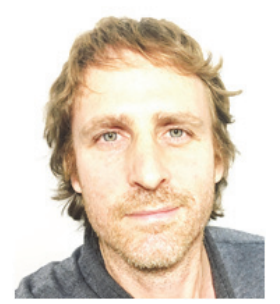

Sergio Busquets-Monge (SM'11) was born in Barcelona, Spain. He received the M.S. degree in electrical engineering and the Ph.D. degree in electronic engineering from the Universitat Politècnica de Catalunya (UPC), Barcelona, in 1999 and 2006, respectively, and the M.S. degree in electrical engineering from Virginia Polytechnic Institute and State University, Blacksburg, VA, USA, in 2001.

From 2001 to 2002, he was with Crown Audio, Inc. Since 2007, he has been an Associate Professor with the Electronic Engineering Department, UPC. His current research interests include standardized/modular power converter design and multilevel conversion.

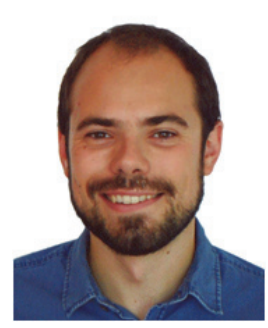

Alber Filba-Martinez (M'19) was born in Mataró, Spain. He received the M.S. and Ph.D. degrees in electrical engineering from the Universitat Politècnica de Catalunya (UPC), Barcelona, Spain, in 2011 and 2016, respectively.

Since 2011, he has been a researcher in the Power Electronics Research Group, UPC. In 2018 he started working as a part-time professor at Tecnocampus Mataró-Maresme, Universitat Pompeu Fabra, Mataró. His research interests include multilevel converters for dc-dc conversion applications, power converters in electric vehicles, and renewable energy systems.

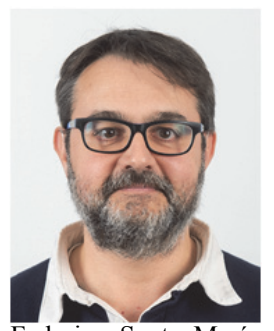

Salvador Alepuz (SM'12) was born in Barcelona, Spain. He received the M.S. and Ph.D. degrees in electrical and electronic engineering from the Universitat Politècnica de Catalunya (UPC), Barcelona, in 1993 and 2004, respectively.

Since 1994, he has been an Associate Professor at the Escola Superior Politècnica, Universitat Pompeu Fabra, Tecnocampus Mataró-Maresme, Mataró, Barcelona. He has been a visiting researcher at the Departamento de Electrónica, Universidad Técnica Federico Santa María, Chile, and the Electrical and Computer Engineering Department, Ryerson University, Toronto, Canada. His fields of interest are multilevel converters, ac power conversion, and predictive control applied to renewable energy systems.

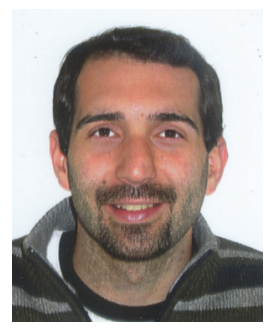

Joan Nicolas-Apruzzese (M'14) was born in Maracaibo, Venezuela. He received the M.S. degree in electrical engineering and the Ph.D. degree in electronic engineering from the Universitat Politècnica de Catalunya (UPC), Barcelona, Spain, in 2008 and 2013, respectively.

Since 2008, he has been a researcher in the Power Electronics Research Group, UPC. His main research interests include multilevel power converters applied to electric vehicles and photovoltaic- and windenergy systems.

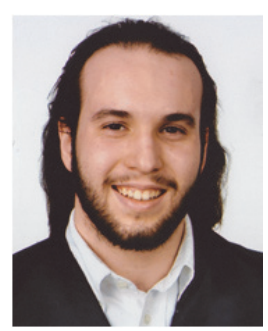

Adria Luque was born in Sabadell, Spain. He received the B.S. degree in industrial technology engineering from the Universitat Politècnica de Catalunya (UPC), Barcelona, Spain, in 2018.

$\mathrm{He}$ is currently pursuing the M.S. degree in industrial engineering and the M.S. degree in automatic control and robotics at UPC. His current research interests include multilevel power conversion.

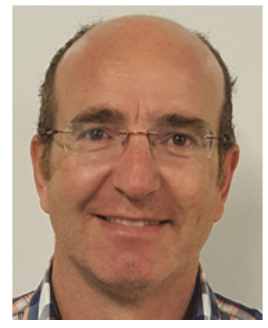

Alfonso Conesa-Roca was born in Barcelona, Spain. He received the M.S. and Ph.D. degrees in electronic engineering from the Universitat Politècnica de Catalunya (UPC), Barcelona, in 1998 and 2006, respectively.

$\mathrm{He}$ is currently an Assistant Professor with the Electronic Engineering Department, UPC. His current research interests include switching-mode power supplies, power architectures, and resonant power conversion.

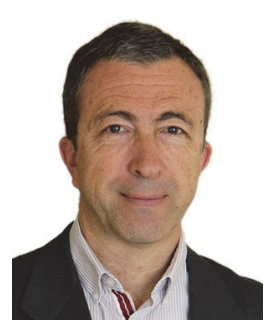

Josep Bordonau (M'89) was born in Sitges, Spain. $\mathrm{He}$ received the M.S. and the Ph.D. degrees in electrical engineering with honors from the Universitat Politècnica de Catalunya (UPC), Barcelona, Spain, in 1984 and 1990, respectively. Since 1991, he has been an Associate Professor with the Electronic Engineering Department, UPC. Since 2018, he is the Master's School Director at EIT InnoEnergy. His current research interests include ac converters, multilevel technology, renewable energies, energy management systems, distributed generation systems, smart grids, and electric/hybrid vehicles. 